\title{
Unresectable Low Grade Glioma
}

National Cancer Institute

\section{Source}

National Cancer Institute. Unresectable Low Grade Glioma. NCI Thesaurus. Code C155829.

Low grade glioma that is not amenable to surgical removal. 